\title{
Tolvaptan response predictors in acute heart failure patients with congestion
}

\author{
Hindun Wilda Risni ${ }^{1}$, Rani Sauriasari ${ }^{*}$, Oriza Satifa ${ }^{2}$ \\ 1 Faculty of Pharmacy, Universitas Indonesia, Depok, Indonesia \\ 2 Pharmacy Department, Harapan Kita National Heart Center, Jakarta, Indonesia
}

\begin{abstract}
Tolvaptan has been used in many countries as an adjunct to diuretic therapy for heart failure. The identification of predictors of response to tolvaptan is essential in developing individual treatment plans, and this study therefore aims to identify responders and predictors to the use of this treatment. A total of 75 acute heart failure patients with congestion receiving tolvaptan were analyzed retrospectively. Clinical parameters after tolvaptan treatment were evaluated to provide an overview of the effectiveness and safety of tolvaptan. A predictive model was created, and logistic regression analysis was performed. The criterion for diuresis response was peak fluid balance of $>-1000 \mathrm{ml}$, while the criterion for sodium response was $>3.5 \mathrm{mEq} / \mathrm{l}$ sodium increase. Clinical parameters of urine volume and fluid balance before and after tolvaptan did not differ significantly, but serum creatinine, eGFR, sodium, potassium, and blood pressure were significantly different. Hypernatremia occurred in one patient. Multivariate analysis of all samples showed that diabetes $(\mathrm{OR}=4.856 ; P=0.006)$ and systolic blood pressure $(\mathrm{SBP})(\mathrm{OR}=1.031 ; P=0.046)$ affected diuresis response. Analysis in hyponatremic patients demonstrated that $\operatorname{sex}(\mathrm{OR}=0.159 ; P=0.033)$ and serum sodium $(\mathrm{OR}=0.83 ; P=0.045)$ affected sodium response. Administration of tolvaptan significantly changed serum creatinine, eGFR, sodium, potassium, and blood pressure. The predictors for diuresis responders were the absence of type 2 diabetes and having higher baseline SBP, while the predictors for sodium responders were being male and having lower baseline serum sodium levels.
\end{abstract}

\section{Keywords:}

Heart failure, Diuresis response, Sodium response, Tolvaptan

\section{INTRODUCTION}

$\mathrm{HF}$ (heart failure) is associated with significant mortality, morbidity, and health expenditure ${ }^{1}$. HF prevalence in the Indonesian population is 5\%, which is higher than Asia as a whole, Europe, and the US ${ }^{2}$. The mortality rate for HF in Southeast Asia is approximately $13 \%{ }^{3}$. Diuretics are used in HF patients to treat dyspnea and edema in those with symptoms and signs of congestion as manifested by excess body fluid ${ }^{4}$. The most widely used diuretics are loop diuretics such as furosemide. Tolvaptan, a V2 (vasopressin 2) receptor antagonist, has been used in many countries as an adjunct to diuretic therapy for HF. In the US, tolvaptan is indicated for hypervolemic or euvolemic hyponatremic patients, including those with acute $\mathrm{HF}^{5}$. In Asian countries, including Indonesia, tolvaptan can also be used in normonatremic HF patients who have volume overload and do not respond to conventional diuretics ${ }^{6-7}$. Various clinical trials and retrospective studies have demonstrated the efficacy and safety of tolvaptan ${ }^{8-13}$.

The EVEREST clinical trial of tolvaptan showed survival rates were not superior to those in the placebo group $^{8}$, but survival rate was shown to increase in hyponatremic patients ${ }^{14}$. Therefore, there are indications that the optimal effect of tolvaptan can be achieved by use in specific populations. The identification of responders to and predictors for tolvaptan use are consequently important for developing individual treatment plans. In addition, the use of tolvaptan is still hampered by its relatively high price. National insurance in Indonesia does not cover tolvaptan, thus, health professionals need a strategy for

\section{*Corresponding author:}

*Rani Sauriasari rani@farmasi.ui.ac.id 
deciding when tolvaptan should be administered. Several studies of predictors of tolvaptan response have been carried out ${ }^{15-19}$, yet many of the findings are difficult to apply in developing countries since the predictors identified are not routinely tested for in clinical practice. This study aims to identify simpler predictors of responders that are expected to assist health professionals in making better therapeutic decisions.

\section{MATERIALS AND METHODS}

\subsection{Sample}

The calculation of sample was based on a rule of thumb that the number of subjects required was 5-50 times the number of independent variables ${ }^{20}$. In this study, 18 independent variables were determined, thus the minimum sample required was 90 subjects. Unfortunately, out of 128 patients using tolvaptan, only 75 patients fulfilled the inclusion and exclusion criteria. Therefore, a total of 75 acute HF patients with congestion who received tolvaptan as an adjunct to conventional therapy in the period 2017 to 2020 were retrospectively evaluated.

Inclusion criteria included adult patients (age $>18$ years) and patients who received tolvaptan with signs of congestion, i.e. evidence of pulmonary congestion, pleural effusion, or peripheral edema. Patients with estimated glomerular filtration rate (eGFR) of $<15 \mathrm{ml} /$ $\min / 1.73 \mathrm{~m}^{2}$, those undergoing renal replacement therapy, patients with sepsis, cardiogenic shock, and patients who did not receive furosemide before and during treatment with tolvaptan were not included in this study. The study received ethical approval from Harapan Kita National Heart Center, Jakarta, Indonesia.

\subsection{Data collection and definition of a responder}

Several clinical parameters were evaluated to give an overview of the effectiveness and safety of tolvap$\tan$. The parameters were urine volume, fluid balance, blood pressure, serum sodium, and serum potassium after administration of tolvaptan as endpoints.

Furthermore, to identify response predictors, the independent variable consisted of demographic profile, baseline clinical parameters, concomitant drugs, and concurrent medical conditions. Baseline parameters were taken before tolvaptan administration. The endpoints included status of diuresis response and sodium response. The criterion for diuresis responder, i.e. patients who responded to the diuretic effect of tolvaptan, was peak fluid balance of >-1000 ml. Furthermore, a sub analysis of sodium response was conducted in hyponatremic patients. The criterion for sodium responder, i.e. patients who responded to effect of sodium increase due to tolvaptan, was a $>3.5 \mathrm{mEq} / \mathrm{L}$ increase in sodium.
Causal analysis of adverse drug reaction (ADR) was performed using the Naranjo algorithm ${ }^{21}$.

\subsection{Statistical analysis}

Bivariate analysis of clinical parameters before and after tolvaptan administration was performed using $t$-paired and Wilcoxon tests, depending on the distribution of data. Bivariate analysis between responders and nonresponders was conducted using chi-squared or Fisher's tests for categorical variables and independent $t$-test or Mann-Whitney test for numerical data. Backward logistic regression was carried out on variables with $P<0.25$ in the bivariate analysis. $P<0.05$ was considered significant. To determine the quality of the regression equation, assessment was carried out using the Hosmer-Lemeshow test. Correlation analysis was performed using Spearman rank correlation coefficient. Values are expressed in mean and standard deviation or 95\% confidence intervals (CI 95\%) for normally distributed data, and median and minimum-maximum for non-normally distributed data. Values are given in $n$ and percent for categorical variables. Statistical analysis was performed using SPSS software, version 23.

\section{RESULTS}

\subsection{Patient characteristics}

Patients involved in the study were patients with advanced heart failure. The mean age of the patients in the study was 56.1 years old. Median left ventricular ejection fraction (LVEF) was $26 \%$, and $67 \%$ of the sample were patients with heart failure with reduced ejection fraction ( $\mathrm{HFrEF}$ ). The etiology of HF was dominated by coronary heart disease, which composed $38.6 \%$ of the total sample. Furthermore, a total of 60 patients had decreased kidney function with eGFR below $90 \mathrm{ml} / \mathrm{min} /$ $1.73 \mathrm{~m}^{2}$. Documented serum electrolyte parameters were means of $129 \mathrm{mEq} / \mathrm{l}$ for sodium and $4 \mathrm{mEq} / \mathrm{l}$ for potassium. Most of the patients (70\%) in the study had hyponatremia. Tolvaptan was administered to patients in varying doses, with most patients receiving a dose of $15 \mathrm{mg} / \mathrm{day}$ with a median duration of three days and a mean initiation time of ten days after admission (Table 1).

\subsection{Alteration in clinical parameters after administration of tolvaptan}

Evaluation of changes in clinical parameters was carried out to provide an overview of the effectiveness and safety of tolvaptan in HF patients. Alteration in parameters is presented in Table 2. Changes of urine volume and fluid balance were not significantly different, with $P$ values of 0.235 and 0.154 , respectively. The other clinical parameters had $P$ values of $<0.05$, meaning 
Table 1. Patient Characteristics.

\begin{tabular}{|c|c|}
\hline Characteristics & Value \\
\hline Age (years) & $56.1(52.7-59.3)$ \\
\hline Male (n) & $45(60)$ \\
\hline Body weight $(\mathrm{kg})$ & $60(33-110)$ \\
\hline Body Mass Index (kg/m2) & $23.72(22.54-24.96)$ \\
\hline Systolic blood pressure (mmHg) & $98.78(94.29-103.49)$ \\
\hline Diastolic blood pressure (mmHg) & $63.11(13.73)$ \\
\hline $\operatorname{LVEF}(\%)$ & $26(13-85)$ \\
\hline \multicolumn{2}{|l|}{ Etiology of HF (n) } \\
\hline Coronary Artery Disease & $29(38.6)$ \\
\hline Hypertension & $9(12)$ \\
\hline Valve disease & $16(21.3)$ \\
\hline Cardiomyopathy & $6(8)$ \\
\hline Infarct & $11(14.7)$ \\
\hline Congenital Heart Disease & $4(5.3)$ \\
\hline \multicolumn{2}{|l|}{ Medical history (n) } \\
\hline Type 2 diabetes & $38(50.7)$ \\
\hline Renal insufficiency & $60(80)$ \\
\hline Hypertension & $20(26.7)$ \\
\hline Infection & $31(41.3)$ \\
\hline Atrial fibrillation & $21(28)$ \\
\hline Previous hospitalization (n) & $51(68)$ \\
\hline \multicolumn{2}{|l|}{ Sign of Congestion (n) } \\
\hline Peripheral edema & $54(72)$ \\
\hline Jugular vein distention & $43(57.3)$ \\
\hline Pleural effusion & $29(38.7)$ \\
\hline Ascites & $39(52)$ \\
\hline Pulmonary congestion & $57(76)$ \\
\hline Urine volume (ml) & $2030(1063.9)$ \\
\hline Fluid balance (ml) & $-606(1151.0)$ \\
\hline Hemoglobin (g/dL) & $11.77(2.54)$ \\
\hline Hematocrit $(\%)$ & $34.89(7.34)$ \\
\hline BUN (mg/dl) & $35.45(30.88-40.69)$ \\
\hline Serum creatinine $(\mathrm{mg} / \mathrm{dl})$ & $1.41(1.26-1.58)$ \\
\hline Glomerular Filtration Rate $\left(\mathrm{ml} / \mathrm{min} / 1.73 \mathrm{~m}^{2}\right)$ & $47.67(41.44-54.85)$ \\
\hline Serum sodium $(\mathrm{mEq} / \mathrm{l})$ & $129(7.1)$ \\
\hline Serum potassium $(\mathrm{mEq} / \mathrm{l})$ & $4(3.9-4.1)$ \\
\hline Tolvaptan dose (mg/day) & $15(7.5-30)$ \\
\hline Tolvaptan duration (days) & $3(1-27)$ \\
\hline Tolvaptan initiation (day-) & $9.9(8.3-11.7)$ \\
\hline Maximum dose of furosemide (mg/hour) & $20(1.67-40)$ \\
\hline \multicolumn{2}{|l|}{ Concomitant drugs (n) } \\
\hline Single diuretic & $39(52)$ \\
\hline Combination of diuretic & $16(21.3)$ \\
\hline Catecholamines & $55(73.3)$ \\
\hline RAAS inhibitor & $71(94.7)$ \\
\hline Beta blocker & $53(70.7)$ \\
\hline Nitrate & $21(28)$ \\
\hline Statin & $43(57.3)$ \\
\hline Anticoagulant & $33(44)$ \\
\hline Antiplatelet & $40(53.3)$ \\
\hline Antimicrobial & $52(69.3)$ \\
\hline
\end{tabular}

LVEF, left ventricular ejection fraction; BUN, blood urea nitrogen; RAAS, renin-angiotensin-aldosterone system.

Table 2. Changes in Clinical Parameters Before and After Tolvaptan.

\begin{tabular}{llll}
\hline \multicolumn{1}{c}{ Clinical Parameters } & Before TLV & After TLV & $\boldsymbol{p}$-value \\
\hline Urine volume $(\mathrm{ml})$ & $2030(1063.9)$ & $2256(1523.7)$ & 0.235 \\
Fluid balance $(\mathrm{ml})$ & $-606(1151.0)$ & $-850(1390.6)$ & 0.154 \\
Systolic blood pressure $(\mathrm{mmHg})$ & $100.9(22.15)$ & $94.5(21.69)$ & $0.009^{*}$ \\
Diastolic blood pressure $(\mathrm{mmHg})$ & $63.1(13.73)$ & $56.89(11.7)$ & $0.001^{*}$ \\
Serum creatinine $(\mathrm{mg} / \mathrm{dl})$ & $1.41(1.26-1.58)$ & $2.39(1.96-2.91)$ & $<0.001^{*}$ \\
Serum sodium $(\mathrm{mEq} / \mathrm{l})$ & $129(7.11)$ & $132.29(7.93)$ & $<0.001^{*}$ \\
Serum potassium $(\mathrm{mEq} / \mathrm{l})$ & $4(3.87-4.13)$ & $4.2(0.7)$ & $0.013^{*}$ \\
\hline
\end{tabular}

TLV, tolvaptan $* P<0.05$ 
meaning there were significant differences between parameters before and after administration of tolvaptan. The results showed that statistically the expected increase in sodium from the use of tolvaptan was significant, with a mean increase of $3 \mathrm{mEq} / \mathrm{l}$.

From Table 3 it can be seen that the prevalence of worsening renal function (WRF), indicated by increase in creatinine serum of $0.3 \mathrm{mg} / \mathrm{dl}$ from baseline, was $28 \%$. In addition, hypo- and hyperkalemia occurred in $7(9.3 \%)$ and $9(12 \%)$ patients, respectively.

One $(1.33 \%)$ patient experienced ADR in the form of hypernatremia, with serum sodium increased to more than $150 \mathrm{mEq} / \mathrm{l}$ after tolvaptan administration. The increase in serum sodium in this patient was $19 \mathrm{mEq} / \mathrm{l}$, from an initial sodium level of 132 to $151 \mathrm{mEq} / \mathrm{l}$. We assessed the ADR causality using the Naranjo algorithm and obtained a score of 4 (the 'possible' category), meaning that ADR may have occurred due to administration of tolvaptan.

\subsection{Response predictors}

Table 4 presents the results of the bivariate analysis performed between independent variables and responses. Further, multivariate logistic regression was conducted for variables with $P<0.25$. Variables in the diuresis response with $P<0.25$ were age, systolic blood pressure, serum creatinine, blood urea nitrogen, tolvaptan dose, infarct etiology, and type 2 diabetes mellitus. For sodium response, analysis was generated only for hyponatremic patients. Variables with $P<0.25$ in sodium response included sex, serum creatinine, blood urea nitrogen, serum sodium, tolvaptan dose, day of tolvaptan initiation, maximal dose of furosemide during tolvaptan treatment, diuretic use other than furosemide, and catecholamine administration.

After multivariate analysis (Table 5), factors that most affected the diuresis response were found to be diabetes mellitus $(\mathrm{OR}=4.856 ; P=0.006)$ and baseline SBP (OR=1.031; $P=0.046)$. Furthermore, factors that most affected sodium response were found to be sex $(\mathrm{OR}=0.159 ; P=0.033)$ and baseline serum sodium levels $(\mathrm{OR}=0.83 ; P=0.045)$. The $P$-value of the HosmerLemeshow test in the regression equation was 0.883 for the diuresis response and 0.257 for the sodium response. Accordingly, there was no difference in observed value in respect of expected value, indicating the equation was well calibrated.

We also performed Spearman correlation analysis between changes in fluid balance as diuresis parameter and baseline serum sodium. The result showed that there was no correlation between changes in fluid balance and baseline serum sodium $(P=0.208, r=-0.15)$.

\section{DISCUSSION}

Increase in urine volume and fluid balance are two parameters used to assess the diuresis response ${ }^{4}$. The non-significant results obtained for these parameters could be due to the characteristics of patients who have severe HF. The study took place in a national referral hospital and so concurrent conditions could potentially have caused poor diuresis response. This result supports the need to identify predictors of responders and nonresponders to diuresis so that tolvaptan administration can be optimized.

The study results demonstrate a significant increase in sodium, of $3 \mathrm{mEq} / \mathrm{l}$. According to meta analysis, the mean increase in sodium after tolvaptan use was $3.48 \mathrm{mEq} / \mathrm{l}^{22}$. This study result only indicates that tolvaptan tends to be effective in increasing patient serum sodium. Comparative studies of sodium elevation with conventional loop diuretics therapy without tolvaptan have been widely performed. Various clinical trials have demonstrated a significant increase in sodium levels in tolvaptan users ${ }^{9,23}$. The mechanism of tolvaptan in increasing sodium lies in its role as an aquaretic. Tolvaptan increases free-water diuresis through V2 receptors in the tubular collecting ducts. In contrast, furosemide removes sodium and water via the Na-K$2 \mathrm{Cl}$ cotransporter along the ascending limb of the loop of Henle ${ }^{24}$, resulting in inhibition of sodium reabsorption. Other significant results were an increase in serum creatinine and a decrease in eGFR that indicated WRF, but these occurrences may be a combination effect of concomitant drugs.

Further analysis of changes in clinical parameters was carried out to evaluate the safety of tolvaptan. The occurrence of hypokalemia and hyperkalemia can be influenced by various factors, including the use of other diuretics such as furosemide, thiazides, and spironolactone, according to their mechanisms of action ${ }^{24}$. Thiazides cause hypokalemia due to an increase in sodium and fluid in the distal tubule and an increased effect of aldosterone, whereas spironolactone acts by inhibiting aldosterone, thus increasing the risk of hyperkalemia ${ }^{24}$.

Based on previous studies, the risk factors for

Table 3. Adverse Events.

\begin{tabular}{lc}
\hline \multicolumn{1}{c}{ Adverse Events } & Number of Patients (n, \%) \\
\hline WRF (creatinine $\geq 0.3 \mathrm{mg} / \mathrm{dl})$ & $22(28)$ \\
Hypokalemia (potassium $<3.5 \mathrm{mEq} / \mathrm{l})$ & $7(9.3)$ \\
Hyperkalemia (potassium $>5.0 \mathrm{mEq} / \mathrm{l})$ & $9(12)$ \\
\hline
\end{tabular}

WRF, worsening renal function. 
Table 4. Bivariate Analysis between Independent Variables and Responses.

\begin{tabular}{|c|c|c|c|c|c|c|}
\hline \multirow[b]{2}{*}{ Variable } & \multicolumn{3}{|c|}{ Diuresis Response $(n=75)$} & \multicolumn{3}{|c|}{ Sodium Response $(n=52)$} \\
\hline & $\begin{array}{l}\text { Responders } \\
\quad(\mathrm{n}=48)\end{array}$ & $\begin{array}{c}\text { Nonresponders } \\
(\mathbf{n}=\mathbf{2 7})\end{array}$ & $P$-value & $\begin{array}{l}\text { Responders } \\
\quad(n=24)\end{array}$ & $\begin{array}{c}\text { Nonresponders } \\
(\mathbf{n}=\mathbf{2 8})\end{array}$ & $P$-value \\
\hline \multicolumn{7}{|l|}{ Baseline paramaters } \\
\hline Age $18-65(n, \%)$ & $41(85.4)$ & $16(59.3)$ & $0.024 *$ & $19(79.2)$ & $18(64.3)$ & 0.382 \\
\hline Male gender & $31(64.6)$ & $14(51.9)$ & 0.404 & $16(66.7)$ & $13(46.4)$ & $0.236^{*}$ \\
\hline BMI (mean, 95\% CI) & $\begin{array}{l}23.42 \\
(22.09-24.81)\end{array}$ & $\begin{array}{l}24.27 \\
(21.9-26.9)\end{array}$ & 0.504 & $\begin{array}{l}23.39 \\
(21.48-25.47)\end{array}$ & $\begin{array}{l}23.74 \\
(21.45-26.26)\end{array}$ & 0.825 \\
\hline $\operatorname{HFrEF}(\mathrm{n}, \%)$ & $33(68.8)$ & $17(63)$ & 0.799 & $14(58.3)$ & $17(60.7)$ & 1 \\
\hline $\begin{array}{l}\text { SBP } \\
(\mathrm{mmHg})(\text { mean, SD) }\end{array}$ & $103.65(25.33)$ & 96.04 (14.09) & $0.099^{*}$ & $99.79(23.22)$ & $96.04(17.5)$ & 0.510 \\
\hline $\begin{array}{l}\text { Creatinine } \\
(\mathrm{mg} / \mathrm{dl})(\text { mean, SD) }\end{array}$ & $1.46(0.65)$ & $1.8(0.91)$ & $0.060 *$ & $1.25(1-1.55)$ & $1.5(1.24-1.82)$ & $0.189 *$ \\
\hline $\begin{array}{l}\text { BUN }(\mathrm{mg} / \mathrm{dl}) \\
(\text { mean, 95\% CI) }\end{array}$ & $\begin{array}{l}32.26 \\
(26.61-39.1)\end{array}$ & $\begin{array}{l}41.9 \\
(35.39-49.68)\end{array}$ & $0.041^{*}$ & $\begin{array}{l}30.24 \\
(21.95-41.63) \\
\end{array}$ & $\begin{array}{l}41.42 \\
(33.97-50.5)\end{array}$ & $0.081^{*}$ \\
\hline $\begin{array}{l}\text { Sodium }(\mathrm{mEq} / \mathrm{l}) \\
(\text { mean, } \mathrm{SD})\end{array}$ & $129.6(6.98)$ & $128.19(7.37)$ & 0.410 & $124.5(109-133)$ & $127(116-134)$ & $0.109 *$ \\
\hline $\begin{array}{l}\text { Potassium }(\mathrm{mEq} / \mathrm{l}) \\
(\text { mean }, 95 \% \mathrm{CI})\end{array}$ & $3.97(3.82-4.13)$ & $4.04(3.82-4.28)$ & 0.619 & $4.06(0.62)$ & $4.19(0.64)$ & 0.457 \\
\hline \multicolumn{7}{|c|}{ TLV and Concurrent Drugs and Medical Conditions } \\
\hline $\begin{array}{l}\text { TLV dose (mg/day) } \\
\text { (median, min-max) }\end{array}$ & $15(7.5-30)$ & $15(7.5-26.25)$ & $0.123^{*}$ & $15(15-25.7)$ & $15(7.5-28.33)$ & $0.143^{*}$ \\
\hline $\begin{array}{l}\text { Initiation day } \\
\text { (median, min-max) }\end{array}$ & $10(1-32)$ & $11(2-29)$ & 0.410 & 7.97 (5.31-11.95) & $10.48(8.47-12.97)$ & $0.224 *$ \\
\hline $\begin{array}{l}\text { Furosemide maxi- } \\
\text { mum dose }(\mathrm{mg} / \mathrm{h}) \\
(\text { median, min-max })\end{array}$ & $20(1.67-40)$ & $25(2.5-30)$ & 0.507 & $10(1.67-30)$ & $25(5-30)$ & $0.003^{*}$ \\
\hline $\begin{array}{l}\text { Combination of } \\
\text { diuretics }(n, \%)\end{array}$ & $11(22.9)$ & $5(18.5)$ & 0.613 & $2(8.3)$ & $10(35.7)$ & $0.048 *$ \\
\hline $\begin{array}{l}\text { Catecholamines } \\
(\mathrm{n}, \%)\end{array}$ & $33(68.8)$ & $22(81.5)$ & 0.355 & $13(54.2)$ & $25(89.3)$ & $0.011^{*}$ \\
\hline $\begin{array}{l}\text { Infarct etiology } \\
(n, \%)\end{array}$ & $5(10,4)$ & $6(22.2)$ & $0.188 *$ & $4(16.7)$ & 5 (17.9) & 1 \\
\hline $\begin{array}{l}\text { Atrial fibrillation } \\
(\mathrm{n}, \%)\end{array}$ & $15(31.3)$ & $6(22.2)$ & 0.570 & $5(20.8)$ & $7(25)$ & 0.980 \\
\hline $\begin{array}{l}\text { Infections } \\
(\mathrm{n}, \%)\end{array}$ & $33(68.8)$ & $20(74.1)$ & 0.824 & $19(79.2)$ & $21(75)$ & 0.980 \\
\hline $\begin{array}{l}\text { Diabetes mellitus } \\
(\mathrm{n}, \%)\end{array}$ & $20(41.7)$ & $19(70.4)$ & $0.032 *$ & $11(45.8)$ & $15(53.6)$ & 0.781 \\
\hline
\end{tabular}

BMI, body mass index; HFrEF, heart failure reduced ejection fraction; SBP, systolic blood pressure; BUN, blood urea nitrogen; TLV, tolvaptan. ${ }^{*} P<0.25$

Table 5. Logistics Regression Results.

\begin{tabular}{|c|c|c|c|}
\hline Variables & $P$-value & OR & CI 95\% \\
\hline \multicolumn{4}{|l|}{ Diuresis Response } \\
\hline \multicolumn{4}{|l|}{ Type 2 diabetes mellitus } \\
\hline Yes & & Reference & \\
\hline No & 0.006 & 4.856 & $1.585-14.881$ \\
\hline Baseline systolic blood pressure & 0.046 & 1.031 & $1.001-1.063$ \\
\hline \multicolumn{4}{|l|}{ Sodium Response } \\
\hline \multicolumn{4}{|l|}{ Sex } \\
\hline Male & & Reference & \\
\hline Female & 0.033 & 0.159 & $0.029-0.859$ \\
\hline Baseline serum sodium & 0.045 & 0.830 & $0.691-0.996$ \\
\hline
\end{tabular}


early hypernatremia in patients taking tolvaptan are baseline serum sodium of $>140 \mathrm{mEq} / \mathrm{l}$, tolvaptan dose of $>7.5 \mathrm{mg}$, and blood urea nitrogen to creatinine ratio of $>20^{25}$. One patient with hypernatremia in this study had baseline sodium of $132 \mathrm{mEq} / \mathrm{l}-\mathrm{a}$ value that was above the total sample mean, a tolvaptan dose of $>7.5 \mathrm{mg}$, and a blood urea nitrogen to creatinine ratio of 42.25 . We also found a high blood urea nitrogen to creatinine ratio in one study patient with a high increase in sodium of $17 \mathrm{mEq} / \mathrm{l}$.

By logistic regression we found that the predictors for diuresis responders were the absence of type 2 diabetes mellitus and having higher baseline SBP. These results are in line with Matsue et al.'s study which states that poor diuresis response was associated with low blood pressure ${ }^{26}$, but the factor observed in the study was diastolic rather than systolic blood pressure. Blood pressure that is too low can interfere with kidney function through decreased perfusion, thereby reducing diuresis response. However, the relationship between SBP and renal function depends on the level of SBP itself $^{27-28}$. SBP of $80-89 \mathrm{mmHg}$ was associated with renal insufficiency (OR=1.2), SBP of $90-149 \mathrm{mmHg}$ was associated with a lower incidence (OR $<1)$, while SBP of above $150 \mathrm{mmHg}$ was associated with an increased incidence of renal insufficiency $(\mathrm{OR}=1.2)^{27}$. Therefore, further research is needed to determine the optimal SBP cut off in responders to tolvaptan. In addition, although statistically significant, the OR that near one might indicate that baseline SBP is not clinically significant in predicting response.

Diabetes can stimulate the patient's hemodynamics, such as increase in RAAS that causes changes in kidney structure, resulting in glomerular hypertrophy or renal fibrosis ${ }^{29}$ that may affect treatment response. In addition, blood glucose contributes to serum osmolality along with blood sodium, potassium, and urea ${ }^{30}$. Arginine vasopressin (AVP) as an antidiuretic hormone is a peptide released from the hypothalamus in response to changes in plasma osmolality ${ }^{31}$. An increase in plasma osmolality-in this case due to an increase in blood glucose in diabetic patients-will cause an increase in $\mathrm{AVP}^{32}$. Meanwhile, kidney damage due to diabetes can reduce the number of aquaporin 2 (AQP2) channels that play a role in water reabsorption. If we use the response predictor suggested by Imamura et al. ${ }^{33}$, namely AQP2/ AVP, generally when a patient's AVP increases and AQP2 decreases, response to diuresis would be diminished. We observed the samples in this study and found that the mean eGFR in nonresponder diabetic patients was lower than responder diabetic patients, which means that there was a higher potential for AQP2 reduction in nonresponders.

Vasopressin levels influence serum sodium levels; therefore diuretic response may be influenced by serum sodium level. However, correlation analysis demonstrated no correlation between changes of fluid balance and baseline serum sodium. This result was aligned with previous study that showed no correlation between diuretic response and serum sodium levels ${ }^{34}$. It also strengthened the present study that showed baseline serum sodium was not predictor for diuresis response.

Logistic regression analysis in hyponatremic patients showed that predictors of sodium response were being male and having a lower level of baseline serum sodium. Sex can affect the body's physiology ${ }^{35}$, resulting in different treatment responses between males and females. However, in previous clinical trials, patients' sodium levels were not directly shown to be a predictor of sodium response. A clinical trial by Hauptman et al. showed that cardiovascular mortality and morbidity were increased in patients with severe hyponatremia (sodium $<130 \mathrm{mEq} / \mathrm{l}$ ), but this finding was not proven in moderate hyponatremia ${ }^{14}$. In another study, it was found that plasma sodium levels were negatively correlated to an increase in sodium, i.e. the lower the baseline plasma sodium level, the higher the sodium increase ${ }^{36}$.

Our study has some limitations. First, it is a retrospective observational study and prospective studies are therefore needed to confirm its results. Second, the sample number is small so that we consider this study as a pilot study; generalization to the population as a whole is not indicated. Third, as there is no control group as a comparison, the analysis of changes in clinical parameters is limited to descriptive explanation without any conclusion being drawn about which therapy is safer and/or more effective. Fourth, the time period for documenting baseline values before tolvaptan treatment is not uniform because of different initiation days for the treatment; also, laboratory tests were not performed every day and thus it is possible that the actual baseline values were different from those recorded.

The use of response predictors is a shared responsibility among health professionals. Clinical pharmacists play a role in recommending tolvaptan when supported by predictors. Given the relatively high price of tolvaptan, they can also refer to or conduct riskcost-benefit analysis with physicians when predictors do not support treatment with tolvaptan. One example is a cost-effectiveness study to hyponatremic patients, demonstrated that cost-effectiveness was more apparent in marked hyponatremic patients ${ }^{37}$ which is aligned with our study result that lower serum sodium is a predictor of response. Health professionals may want to prioritize tolvaptan to marked rather than mild hyponatremic patients. The accuracy of risk-benefit analysis would be improved by considering the specific predictors indicated by previous studies when health facilities are adequate. By utilizing response predictors it is expected that individual treatment plans in acute HF patients with congestion will be improved. 


\section{CONCLUSIONS}

While there was no significant change in clinical parameters for urine volume and fluid balance after administration of tolvaptan, serum creatinine, eGFR, serum sodium, serum potassium, and blood pressure changed significantly. The use of tolvaptan tends to be safe in patients with acute HF with congestion. The absence of type 2 diabetes mellitus and higher baseline SBP can be good predictors for diuresis responders, whereas predictors for sodium response are being male and having lower baseline serum sodium level.

\section{ACKNOWLEDGMENT}

The authors are grateful to the Directorate of Research and Community Engagement, Universitas Indonesia to give us financial support through Q1Q2 Grant No. (NKB-0201/UN2.R3.1/HKP.05.00/2019).

\section{Conflict of interest}

The authors declare no conflict of interests.

\section{Funding}

This study was supported by Q1Q2 Grant from Directorate of Research and Community Engagement, Universitas Indonesia (NKB-0201/UN2.R3.1/HKP.05. 00/2019).

\section{Ethics approval}

The study was approved by Ethics Committee of Harapan Kita National Heart Center, Jakarta, Indonesia, No. LB.02.01/VII/493/KEP 091/2020.

\section{Article info:}

Received July 1, 2021

Received in revised form September 12, 2021

Accepted October 3, 2021

\section{REFERENCES}

1. Roger VL. Epidemiology of heart failure. Circ Res. 2013;113 (6):646-59.

2. Reyes EB, Ha JW, Firdaus I, Ghazi AM, Phrommintikul A, Sim $\mathrm{D}$, et al. Heart failure across Asia: Same healthcare burden but differences in organization of care. Int J Cardiol. 2016;223(15): 163-7.

3. MacDonald MR, Tay WT, Teng TK, Anand I, Ling LH, Yap J, et al. Regional Variation of Mortality in Heart Failure With Reduced and Preserved Ejection Fraction Across Asia: Outcomes in the ASIAN-HF Registry. J Am Heart Assoc. 2020; 9(5): $\mathrm{e} 014512$.

4. Ponikowski P, Voors AA, Anker SD, Bueno H, Cleland JGF, Coats AJS, et al. 2016 ESC Guidelines for the diagnosis and treatment of acute and chronic heart failure: The Task Force for the diagnosis and treatment of acute and chronic heart failure of the European Society of Cardiology (ESC)Developed with the special contribution of the Heart Failure Association (HFA) of the ESC. Eur Heart J. 2016;37(27):2129-200.

5. Highlights of Prescribing Information: Samsca. Tokyo, Japan: Otsuka Pharmaceutical Co. Ltd.; 2021.

6. Indonesian Heart Association Working group of Cardiometa- bolic Disease and Heart Failure. Consensus of Fluid Therapy in Heart Failure. Indonesia; 2020.

7. Tsutsui $\mathrm{H}$, Isobe $\mathrm{M}$, Ito $\mathrm{H}$, Ito $\mathrm{H}$, Okumura $\mathrm{K}$, Ono M, et al. JCS 2017/JHFS 2017 Guideline on Diagnosis and Treatment of Acute and Chronic Heart Failure-Digest Version. Circ J. 2019; 83(10):2084-184.

8. Konstam MA, Gheorghiade M, Burnett JC Jr, Grinfeld L, Maggioni AP, Swedberg K, et al. Efficacy of Vasopressin Antagonism in Heart Failure Outcome Study With Tolvaptan (EVEREST) Investigators. Effects of oral tolvaptan in patients hospitalized for worsening heart failure: the EVEREST Outcome Trial. JAMA. 2007;297(12):1319-31.

9. Gheorghiade M, Konstam MA, Burnett JC Jr, Grinfeld L, Maggioni AP, Swedberg K, et al. Efficacy of Vasopressin Antagonism in Heart Failure Outcome Study With Tolvaptan (EVEREST) Investigators. Short-term clinical effects of tolvaptan, an oral vasopressin antagonist, in patients hospitalized for heart failure: the EVEREST Clinical Status Trials. JAMA. 2007; 297(12):1332-43.

10. Konstam MA, Kiernan M, Chandler A, Dhingra R, Mody FV, Eisen H, et al. Short-Term Effects of Tolvaptan in Patients With Acute Heart Failure and Volume Overload. J Am Coll Cardiol. 2017;69(11):1409-19.

11. Nakano Y, Mizuno T, Niwa T, Mukai K, Wakabayashi $H$, Watanabe A, et al. Impact of Continuous Administration of Tolvaptan on Preventing Medium-Term Worsening Renal Function and Long-Term Adverse Events in Heart Failure Patients with Chronic Kidney Disease. Int Heart J. 2018;59(1):105-11.

12. Uemura Y, Shibata R, Takemoto K, Uchikawa T, Koyasu M, Ishikawa S, et al. Safety and Efficacy of Long-Term Use of Tolvaptan in Patients With Heart Failure and Chronic Kidney Disease. Circ J. 2017;81(11):1736-8.

13. Kinugawa K, Sato N, Inomata T, Yasuda M, Shimakawa T, Fukuta Y. Real-World Effectiveness and Tolerability of Tolvaptan in Patients With Heart Failure-Final Results of the Samsca Post-Marketing Surveillance in Heart Failure (SMILE) Study. Circ J. 2019;83(7):1520-7.

14. Hauptman PJ, Burnett J, Gheorghiade M, Grinfeld L, Konstam MA, Kostic D, et al. Clinical course of patients with hyponatremia and decompensated systolic heart failure and the effect of vasopressin receptor antagonism with tolvaptan. J Card Fail. 2013;19(6):390-7.

15. Imamura $T$, Kinugawa $K$, Shiga $T$, Kato $N$, Muraoka $H$, Minatsuki S, et al. Novel criteria of urine osmolality effectively predict response to tolvaptan in decompensated heart failure patients-association between non-responders and chronic kidney disease. Circ J. 2013;77(2):397-404.

16. Nakada Y, Okayama S, Nakano T, Ueda T, Onoue K, Takeda Y, et al. Echocardiographic characteristics of patients with acute heart failure requiring tolvaptan: a retrospective study. Cardiovasc Ultrasound. 2015;13:27.

17. Imamura T, Kinugawa K. Urine Aquaporin-2: A Promising Marker of Response to the Arginine Vasopressin Type-2 Antagonist, Tolvaptan in Patients with Congestive Heart Failure. Int J Mol Sci. 2016;17(1):105.

18. Sato Y, Dohi K, Watanabe K, Tanimura M, Takeuchi T, Sugiura E, et al. Combination of Urinary Sodium/Creatinine Ratio and Plasma Brain Natriuretic Peptide Level Predicts Successful Tolvaptan Therapy in Patients With Heart Failure and Volume Overload. Int Heart J. 2016;57(2):211-9.

19. Kadota M, Ise T, Yagi S, Iwase T, Akaike M, Ueno R, et al. Response Prediction and Influence of Tolvaptan in Chronic Heart Failure Patients Considering the Interaction of the ReninAngiotensin-Aldosterone System and Arginine Vasopressin. Int Heart J. 2016;57(4):461-5.

20. Madiyono B, Mz MS, Sastroasmoro S, Budiman S, Purwanto SH. Sample size estimation. In: Sastroasmoro S, Ismael S, editors. Basics of Clinical Research Methodology. Jakarta: Sagung Seto; 2014. p. 381-2. 
21. Naranjo CA, Busto U, Sellers EM, Sandor P, Ruiz I, Roberts EA, et al. A method for estimating the probability of adverse drug reactions. Clin Pharmacol Ther. 1981;30(2):239-45.

22. Wang C, Xiong B, Cai L. Effects of Tolvaptan in patients with acute heart failure: a systematic review and meta-analysis. BMC Cardiovasc Disord. 2017;17(1):164.

23. Matsue Y, Suzuki M, Torii S, Yamaguchi S, Fukamizu S, Ono $\mathrm{Y}$, et al. Clinical Effectiveness of Tolvaptan in Patients With Acute Heart Failure and Renal Dysfunction. J Card Fail. 2016; 22(6):423-32.

24. Ellison DH. Clinical Pharmacology in Diuretic Use. Clin J Am Soc Nephrol. 2019;14(8):1248-57.

25. Hirai K, Shimomura T, Moriwaki H, Ishii H, Shimoshikiryo T, Tsuji D, et al. Risk factors for hypernatremia in patients with short- and long-term tolvaptan treatment. Eur J Clin Pharmacol. 2016;72(10):1177-83.

26. Matsue Y, Ter Maaten JM, Suzuki M, Torii S, Yamaguchi S, Fukamizu S, et al. Early treatment with tolvaptan improves diuretic response in acute heart failure with renal dysfunction. Clin Res Cardiol. 2017;106(10):802-12.

27. Zhang YP, Zuo XC, Huang ZJ, Kuang ZM, Lu MG, Duan DD, et al. The impact of blood pressure on kidney function in the elderly: a cross-sectional study. Kidney Blood Press Res. 2013; 38(2-3):205-16.

28. Yamamoto T, Nakayama M, Miyazaki M, Matsushima M, Sato T, Taguma Y, et al. Relationship between low blood pressure and renal/cardiovascular outcomes in Japanese patients with chronic kidney disease under nephrologist care: the Gonryo study. Clin Exp Nephrol. 2015;19(5):878-86.
29. Alicic RZ, Rooney MT, Tuttle KR. Diabetic Kidney Disease: Challenges, Progress, and Possibilities. Clin J Am Soc Nephrol. 2017;12(12):2032-45.

30. Ebonwu EO, Nagel SE, Repsold L, Pillay TS. Critical evaluation of equations for serum osmolality: Proposals for effective clinical utility. Clin Chim Acta. 2020;510:79-87.

31. Wasilewski MA, Myers VD, Recchia FA, Feldman AM, Tilley DG. Arginine vasopressin receptor signaling and functional outcomes in heart failure. Cell Signal. 2016;28(3):224-33.

32. Ishikawa SE, Schrier RW. Pathophysiological roles of arginine vasopressin and aquaporin-2 in impaired water excretion. Clin Endocrinol (Oxf). 2003;58(1):1-17.

33. Imamura T, Kinugawa K, Fujino T, Inaba T, Maki H, Hatano M, et al. Increased urine aquaporin-2 relative to plasma arginine vasopressin is a novel marker of response to tolvaptan in patients with decompensated heart failure. Circ J. 2014;78(9):2240-9.

34. Takagi K, Sato N, Ishihara S, Sone M, Tokuyama H, Nakama K, et al. Effects of tolvaptan on urine output in hospitalized heart failure patients with hypoalbuminemia or proteinuria. Heart Vessels. 2018;33(4):413-20.

35. Miller VM. Why are sex and gender important to basic physiology and translational and individualized medicine? Am J Physiol Heart Circ Physiol. 2014;306(6):H781-8.

36. Umbrello M, Mantovani ES, Formenti P, Casiraghi C, Ottolina $\mathrm{D}$, Taverna M, et al. Tolvaptan for hyponatremia with preserved sodium pool in critically ill patients. Ann Intensive Care. 2016;6(1):1.

37. Lee MY, Kang HJ, Park SY, Kim HL, Han E, Lee EK. Costeffectiveness of tolvaptan for euvolemic or hypervolemic hyponatremia. Clin Ther. 2014;36(9):1183-94. 